\title{
PERIGLACIAL PHENOMENA AFFECTING NUCLEAR WASTE DISPOSAL
}

\author{
HEIKKI NIINI, NURIA MARCOS and TIMO RUSKEENIEMI
}

HEIKKI NIINI, NURIA MARCOS and TIMO RUSKEENIEMI, 1997. Periglacial phenomena affecting nuclear waste disposal. Bull. Geol. Soc. Finland 69, Part 1-2, 109-114.

Slow future changes in astronomic phenomena seem to make it likely that Finland nll suffer several cold periods during the next 100,000 years. The paper analyses the characteristics of the periglacial factors that are most likely to influence the long-term safety of high-level radioactive waste disposed of in bedrock. These factors and their influences have been divided into two categories, natural and human. It is concluded that the basically natural phenomena are theoretically better understood than the complicated phenomena caused by man. It is therefore important in future research into periglacial phenomena, as well as of the disposal problem, to emphasize not only the proper applications of the results of natural sciences, but especially the effects and control of mankind's own present and future activities.

Keywords: radioactive waste, underground disposal, bedrock, safety, periglacial environment, permafrost, ground-water flow, greenhouse effect, Finland

Heikki Niini, Laboratory of Engineering Geology and Geophysics, Helsinki University of Technology, PL 6200, FIN-02015 TKK

\section{INTRODUCTION}

Dealing with periglacial phenomena in connection with the final disposal of nuclear or radioactive wastes is based on a geologically natural assumption: the time period involved-due to the slow decay of radioactive waste-is long enough to include potential future periglacial climate periods.

Slow changes in the planetary movements of the earth seem to make it likely that Finland will suffer a very cold period leading to a full-scale ice age already about 23,000 years from the present time, and several alternating warmer and colder periods will appear during the next 100,000 years (Matthews 1984, Eronen 1985). The natural reason of the climate variations is the co-influence of cyclic changes in three independent planetary movements that have a different length of the cycle:

(1)precession of the equinoxes, caused by the circulation of the position of the rotation axis, 
(2)obliquity of the Earth, i.e., the tilt of the rotation axis of the Earth in regard to the orbit plane,

(3)exentricity of the orbit, i.e., the elliptic form of the route of the Earth around the Sun.

In addition, climatic changes may be caused by long-term periodic changes in the radiation from the Sun. All these factors belong to the astronomical phenomena, contributing to the ones brought about by the Earth's "own, purely geological," factors.

The cold periods may involve real ice ages within continental areas in polar regions; it is most likely that periglacial conditions prevail in these areas before and after each ice age, and during an ice age also in the adjacent areas.

Without considering astronomical forecasts, the likelihood of a repeated occurrence of periglacial conditions in northern Europe during the next 100,000 years can also be assumed on the basis of rough extrapolation from the analogical Quaternary geological history (Eronen 1990, 1992) and the thermal history of bedrock revealed by measurements of temperature gradients in deep drill holes (Kukkonen 1989).

Periglacial factors most likely affect the future safety of the high-level radioactive wastes disposed of in the bedrock. These factors may be divided into three different conceptual categories:

(1)the natural processes taking place in, or affecting, the geological formations and materials that form the physical framework for the future underground disposal facilities,

(2)the surficial phenomena that affect mankind's future living conditions in the area,

(3)the periglacial phenomena or conditions that offer indirect contributions, either natural analogues or new study methods, applicable to the planning and realization of the disposal concept.

\section{NATURAL PERIGLACIAL PROCESSES}

For a proper planning of nuclear waste disposal, it is necessary to know with adequate accuracy, not only the present geological conditions at the relevant disposal sites and in their surroundings, but also all possible changes that may occur in the future and which are not directly observable at present. However, there are two logical ways to make natural observations about the periglacial (as well as completely glacial) phenomena and conditions:

(1)observations at the disposal areas about the present conditions that are interpreted as results of ancient periglacial phenomena,

(2)observations of similar, or analogue, factors from present periglacial areas.

The two methods, of course, should be used simultaneously and deliberately combined.

\section{Surficial phenomena}

Periglacial geological phenomena that may be crucially different from the presently active ones include weathering and erosion. Frost action, which easily breaks fresh rock surfaces and pieces into small particles, is known to be much more effective in periglacial condition than it is elsewhere. Combined with ice and wind erosion, it has in places produced steep-sloped valleys (gorges) in the bedrock, about which Lintinen (1997) described nice examples from Antarctica. However, compared with the total Quaternary valley erosion in southern Finland that seems to have been able to produce topographic differences of the order of few dozens of metres at the most (see Niini 1968, 1989), it does not seem probable that periglacial wind erosion could cause an erosion of the bedrock significant for the disposal of wastes in a depth of about half a kilometre.

The action of wind in periglacial conditions may, however, be significant in another way. The wind may carry considerable quantities of salt from the open sea a long distance to the inland. In addition, there are salt lakes in Antarctica's climatically dry areas far from the ocean. The salt has also intruded and partly precipitated in the pores or cracks of the ground along with the percolation of groundwater. 
Significant meteorological transport of salt has not been observed or concluded in Finlandlet alone southern Finland-but it is clear that, from the point of view of waste disposal, a possible absorption of salt would be a major factor controlling the chemistry of bedrock fractures and, hence, both the weathering of the rocks and the chemical stability of the waste canister materials. Due to the complicated movements and chemical behaviour of the groundwater, such an influence could reach also deeper levels in the bedrock. Therefore, it is important to study those future possibilities - or to model such periglacial scenarios-in which there would be a dry climate with salt lakes and/or an ocean close to the disposal site chosen. Such conditions could be caused by, for instance, a remarkable rise of the ocean level in relation to vertical land movements.

\section{Periglacial bedrock conditions}

A major phenomenon commonly connected with periglacial conditions is permafrost. Apparently, a permafrost layer in the ground effectively decreases the water conductivity of the bedrock and thus prevents the flow of liquid-state groundwater. This would create a favourable condition, because the upward spreading of radioactive materials from the waste repository along with groundwater is then restrained. However, recent observations from Antarctica (Kapitsa et al. 1996) as well as bedrock temperature observations and theoretical geophysical calculations from Finland (Ruotoistenmäki \& Lehtimäki 1997) indicate that the permafrost layer may not be coherent: it is likely that the permafrost layer associated with a continental glacier is perforated by holes through which flowing groundwaters are connected with surficial waters or subglacial lakes (Niini \& Ruskeeniemi 1991).

Under a continental glacier several kilometres thick, the hydraulic gradients around the permafrost holes may be remarkable, forcing the groundwater circulation to reach a considerable depth. Due to the heat behaviour and temperature gradient in the bedrock, it is likely that the thickness of the permafrost layer is at its maximum in the periglacial zone around the glacier, where the ice sheet does not form a thick isolating layer that hampers the heat conduction from the bedrock to the air. There the freezing of groundwater presses the dissolved ions downward as a concentrated saline front (Niini \& Blomqvist 1994), which may leave chemical traces in the mineral coatings of bedrock fractures in a depth of about one kilometre.

In the ice-marginal areas, at the melting stage of the glacier, the hydraulic gradient may be very high because it is augmented by the retreating marginal slope of the glacier and by new surface-topographical expressions, such as gorges. Then, the groundwater pressure may burst out along rock fractures with a power even breaking fresh rock. Such outbursts could also locally increase the water conductivity of the bedrock. Punkari (1994) has presented that the groundwater circulation temporarily increased by the melting of the glacier may under certain conditions reach a depth of 600 metres; this would then affect the waste repository conditions rapidly and severely.

At the same time and also later, as the thickness of the glacier is decreasing, an isostatic rebound of the Earth's crust also causes changes in the general inclination (tilt) of the surface and, therefore, also in the hydraulic gradient. It seems that the gradient change is cyclic, so that, e. g., in western Finland the hydraulic gradient would gradually, during thousands of years after each retreat of the glacier margin, change from a western direction to an eastern one. This succession is well documented in many lake basins.

Other cases in which the hydraulic gradient and even the water conductivity of the bedrock are susceptible to notable changes include sudden vertical faults of the crust. These cases could be considered periglacial in the sense that they seem to have taken place in the areas around a melting glacier where a periglacial climate prevails. They may be genetically connected with the stepwise retreat of the glacier margin. There are a lot of observations interpreted to prove 
such neotectonic movements in Fennoscandia (Vuorela et al. 1987).

The magnitude of the neotectonic faults is, however, relatively small. Even the most prominent cases only reveal a vertical displacement of the order of some dozens of metres. This means that it is unlikely that such a local increase of the hydraulic gradient would significantly affect the regional hydraulic gradient at half a kilometre's depth, the probable level of a waste repository.

Each neotectonic fault also denotes a creation or growth of an individual fracture zone that may conduct water easier than the former intact bedrock. However, this factor most likely has still much less effect than the growth of the hydraulic gradient, because there are anyway a large number of water-conducting fractures of variable sizes and orientations in the uppermost layer (200-300 metres thick) of the bedrock (Niini 1968, 1987).

\section{MANKIND'S VITAL CONDITIONS}

From the point of view of human life, glaciation of an area apparently deteriorates environmental conditions severely. In this respect, the records from the geological history are obvious: on the whole, life on a thick glacier has been minimal. But how can we extrapolate this fact to the future and to the associated periglacial conditions from the point of view of waste disposal?

The planning of the final disposal of nuclear wastes takes place adapting the so-called principle of conservatism, which says that its safety assessment must be based, not on the most likely, but on the worst, yet reliable, scenarios (OECD 1995). During very cold climatic periods, due to the severe environmental conditions, there would not be significant life in the disposal area, which could be affected by the radioactivity possibly released. In this respect, a cold climate with glaciations and associated periglaciations denotes a more favourable scenario than one with no glaciation. However, this is not an adequate reason for rejecting the "favourable" cold climate scenarios; any scenario must first be considered internally consistent and only its summary results should be compared with other scenarios. Therefore, the scenarios with glacial and periglacial conditions must be taken into account and considered with both their favourable (sparse population) and forementioned less favourable (hydrogeological etc.) aspects.

Other human aspects to be considered include the effects of man's variable activities. Late Quaternary records have proved a geologically fast development in the history of mankind. Man's adaptation to new circumstances has been unique and his influence on nature immense. These facts make it very difficult to predict man's activities in future periglacial conditions. If the population continues to grow, people may have the need and ability to construct towns even on glaciers. Actually, the most important aspect in this respect is the global control of the population growth.

Another probable severe influence of man is the uncontrolled combustion of fossil fuels, which may involve a rise of the average global air temperature, the so-called greenhouse effect. At present, when the magnitude of its effects is still argued among scientists, the greenhouse effect must be regarded as an important future scenario to be continuously investigated. So far, it has been estimated that the rise in average global temperature is only capable of slightly delaying the forthcoming cold periods caused by the forementioned astronomical factors.

Anyway, it could be possible that the temperature rise of the greenhouse effect is followed by a rise of the ocean level, changes in wind and ocean stream directions, and - either an increase or a decrease in glacier volumes. If the glaciations then become less severe but will last longer, also the strength of the periglacial conditions, particularly the penetration of the permafrost in the bedrock, may differ radically from what the geological records have shown up to now. For instance, a longer periglacial period could make a thicker permafrost layer possible.

The globally severe human effects on the environmant are-so far-mostly uncontrolled, 
but it is necessary to remember the opposite, too: man's capability of changing the conditions to the better direction. This should not be a wish only, but we should actually work aiming at better geologically-based technical applications that can be considered in the safety assessments and eventually applied in reality.

In accordance with the forementioned, the future scenarios should take into account the following possibilities: even in periglacial and glacial conditions it is possible for man to technically monitor the phenomena in and around a waste repository, to excavate openings to the repository, to repair damages, and to transport the wastes to other sites, as well as to treat them with processes better than the present ones.

As a conclusion, careful continuous investigation of the past periglacial geological and biological conditions is necessary. Anyway, the use of the results in planning the final disposal of nuclear waste must take place through a proper adaptation of several possible scenarios each of which must be internally consistent.

\section{Indirect effects}

The periglacial phenomena or conditions that offer indirect contributions to the planning and realization of the final disposal of nuclear waste can be grouped on the basis of two aspects: natural analogues and new study methods offered.

The first group comprises those cases that offer natural analogues applicable to the waste disposal problems. All suitable field studies in other than the disposal areas belong to this group. Such more or less analogous periglacial conditions are found and can be observed in connection with the present continental glaciers, in Antarctica, northern Canada, and Greenland, in particular. Certain subfactors can also be studied in the present mountain glaciers, even in northern Fennoscandia. Nevertheless, for a proper interpretation of such analogies, it is important to pay attention to any differences in other geological conditions (such as topography, regolith stratigraphy, bedrock structure, and mineralogical and chemical composition) and the global astronomic-climatic position.

The applicability of these cases to the waste disposal problems in Finland is, however, not dependent on the overall similarity of the cases with the circumstances of southern Finland but rather on a detailed analysis of the influencing physical, chemical, and biological factors, on the basis of which new compilations should be made in a deducing manner. From the point of view of practical analogue applications, new additional observations on important details and interdependences between, e.g., permafrost, weathering, groundwater, isostatic movements, and temperature changes, are still necessary. In this respect, the on-going study of the present periglacial areas is highly appreciable.

The other group of indirect effects consists of the cases that have offered or can offer new study methods, including both the geological results achieved and the methodological analogies applicable to other areas or problems. In this respect, the development and experiments within the use of several geophysical methods as well as the isotopic (age) determinations deserve a praise.

\section{CONCLUSION}

Based on astronomic calculations, it is very likely that the final repository sites for the Finnish high-level radioactive wastes will be repeatedly subject to long-lasting glacial and periglacial conditions. These conditions and the response to them by the geological formations and materials form the physical and chemical framework for the future underground nuclear waste repositories.

The periglacial factors that most likely affect the safety of the waste disposal were divided into two categories, natural and human. At this stage, it is obvious that the basic natural periglacial phenomena are theoretically relatively well understood, but the human influences and the future natural conditions are more ob- 
scure: this applies both to the state of knowledge about the effect of the present human activities on the future development of climatic changes, and to man's future technical potential to solve the problems caused by these climatic and human changes.

When trying to take into account the future periglacial factors in connection with all other possible factors from the point of view of nuclear waste disposal, we have to emphasize, not only the proper applications of the results of the natural sciences, but especially the influence chains caused by man's own present and future activities and decisions. While we cannot control inadvertent human effects consistently, we should prefer such disposal solutions that mitigate the indispensable responses by future generations.

\section{REFERENCES}

Eronen, Matti, 1985. Astronominen ilmastonvaihteluteoria ja jääkausiaikojen jaksollisuus. Summary: Astronomical theory of climatic change and periodicity of ice ages. Terra 97: 4, 3-19.

Eronen, Matti, 1990. Muuttuva ilmasto (The changing climate). Terra 102: 4, 220-238.

Eronen, Matti, 1992. Quaternary chronostratigraphy -a review. Bull. Geol. Soc. Finland 64, 135-137.

Kapitsa, A. P. \& Ridley, J. K. \& Robin, G. de Q. \& Siegert, M. J. \& Zotikov, I. A., 1996. A large deep freshwater lake beneath the ice of central East Antarctica. Nature 381, 684-686.

Kukkonen, Ilmo, 1989. Terrestrial heat flow in Finland, the central Fennoscandian Shield. Geological Survey of Finland, Report YST-68, 99 pages + 3 Appendices.
Lintinen, Petri, 1997. Article in this proceedings Volume.

Matthews, J. V., 1984. The astronomical climate index and its value for predicting future climate. In: Proceedings of Workshop on Transitional Processes (Ed. W. F. Heinrich), 1982, Ottawa. Atomic Energy of Canada Ltd. - 7822, 40-57.

Niini, Heikki, 1968. A study of rock fracturing in valleys of Precambrian bedrock. Fennia 97: 6, $1-60$.

Niini, Heikki, 1987. Bedrock fractures affecting land uplift. Geological Survey of Finland, Special Paper 2, 51-54.

Niini, Heikki, 1989. Glacial sculpture in bedrock valleys differing in orientation. Geological Survey of Finland, Special Paper 7, 19-24.

Niini, Heikki \& Blomqvist, Runar, 1994. Kvartääritutkimus ja rakokemia. Summary: Quaternary geology and fracture geochemistry. Acta Univ. ouluensis. A 251, 79-91.

Niini, Heikki \& Ruskeeniemi, Timo, 1991. Palmottujärven uraaniesiintymän geologinen historia ja tulevaisuus. Esitelmäraportti IGE-JYT 3-91, 14 pages.

OECD, 1995: The Environmental and Ethical Basis of Geological Disposal-A Collective opinion of the NEA Radioactive Waste Management Committee. Nuclear Energy Agency of OECD, Paris, 30 pages.

Punkari, Mikko, 1994. Subglasiaalinen hydrologia harjujen synnyn selittäjänä. Summary: Subglacial hydrology explaining the origin of eskers. Geologi 1: 46, 3-7.

Ruotoistenmäki, Tapio \& Lehtimäki, Jukka, 1997. Article in this proceedings volume.

Vuorela, Paavo \& Kuivamäki, Aimo \& Paananen, Markku, 1987. Neotectonic bedrock movements. A preliminary survey of the Pasmajärvi fault. Geological Survey of Finland, Nuclear Waste Disposal Research, Report YST-57, 15 pages. 